\title{
Artificial Intelligence and the Phenomenology of Flesh
}

\author{
JAMES MENSCH
}

A. M. Turing argued that there was "little point in trying to make a 'thinking machine' more human by dressing it up in ... artificial flesh." We should, instead, draw "a fairly sharp line between the physical and the intellectual capacities of a man" (434). For over fifty years, drawing this line has meant disregarding the role flesh plays in our intellectual capacities. Correspondingly, intelligence has been defined in terms of the algorithms that both men and machines can perform. I would like to raise some doubts about this paradigm in artificial intelligence research. Intelligence, I believe, does not just involve the working of algorithms. It is founded on flesh's ability to move itself, to feel itself, and to engage in the body projects that accompanied our learning a language. This implies that to copy intelligence - i.e., to produce an artificial version of it - the flesh that forms its basis must also be reproduced.

I.

I shall begin with some general remarks about the role of the body in our awareness of the world. This awareness has a "first-person character." It is always awareness from a particular point of view - a "here" that no one else shares. Behind this is the fact of embodiment, i.e., the fact that different bodies cannot occupy the same space and, hence, cannot share the same "here." Embodiment also underlies the particular foreground-background structure of experience. The view I have of some object is surrounded by a horizon or connected series of views that I 
could have were I to shift my body's position and view the object from elsewhere. Every time I do take a new position, a new view of the object achieves prominence. It becomes the foreground, while the other perspectives form the background. Now, when I assume an impersonal third-person perspective and speak of the object in itself, that is, the object as it is simultaneously available to all perspectives, I dispense with this foreground-background structure. ${ }^{1}$ Doing so, however, I also dispense with my awareness of the object. This is because this foreground-background structure is essential to consciousness. In fact, it is consciousness in its intentional structure. Consciousness perceptually intends or directs itself to an object by bringing one of its aspects to the foreground and relegating the rest to the background. To posit an object "absolutely" without this structure is, then, to posit it in a way that it can never be intended by consciousness. In Merleau-Ponty's words, "the absolute positing of a single object is the death of consciousness" (71). This is because the very notion of consciousness as intentional presupposes its embodiment. Our having a body gives our consciousness the position from which it intends.

Because I can move my body, this position is not fixed. The motility that my body affords allows me to have a whole series of views of the object. In my experience of the object there is a correlation between my bodily movement and the appearing of the object. The horizon of this appearing is set by my movement. I move myself and the object appears differently. Now, each time I do move, I experience not just a change in the "optical" sensations of the object. My sensations of my body, the "kinesthetic" sensations that allow me to sense its movement, are also present. Describing their relation, Husserl writes: "[T]he running off of the optical and the change of the kinesthetic [sensations] do not occur alongside each other, but rather proceed in 
the unity of an intentionality that goes from the optical datum to the kinesthetic and through the kinesthetic leads to the optical" ("Ms. C 16 IV," 40b). ${ }^{2}$ For example, I reach for a glass that I see. As my hand closes about it, I feel its weight. As I bring it to my mouth, I adjust the amount of tension and the force of my arm. I continually make such adjustments as I tilt the glass and drink from it, thereby decreasing its weight. The "unity of intentionality" that Husserl refers to points to the fact that optical and kinesthetic sensations are both involved in the appearing of the object. The glass is not a mere "phantom," but rather a real object with weight precisely because my own bodily sensations form part of its appearing (see "Ms. D 12 II," 11). To intend the object as "real" is, then, to include in its intention its relation to the body.

Husserl in this context speaks of "the kinesthetically motivated presentation of objects" ("Ms. D 12 II," 5). My bodily abilities set the parameters for the ways in which I can present objects to myself. They determine, for example, whether an object is in or out of reach, whether it is graspable or too heavy to handle, etc. As I make my way in the world, I make use of the information I have built up since childhood of what I can and cannot do. Within this context my kinesthetic sensations play a motivational role in my making objects present to myself. Such sensations do not just inform me of my present situation with regard to some object. They also prompt me to adjust my behavior. Thus, feeling an object slipping from my hand, I tighten my grasp as I bring it towards me. To get a better look, I stand on my toes and crane my neck. In the context of my knowledge of my bodily "I can," my kinesthetic sensations motivate the specific actions I take to make objects present. ${ }^{3}$ Without such sensations, then, I lose the full use of this "I can." This loss, however, is the loss of the horizon through which I gain my knowledge of the object. $^{4}$ 
II.

It may be objected that the fact that our grasp of objects involves our bodies does not prevent machines from imitating our intelligence. They are, after all, physical objects. Thus, one could well imagine building into their processing an analogue of the foreground-background structure that characterizes consciousness. As for kinesthetic sensations, there already exist machines that handle objects. They monitor their weight and adjust the pressure that they apply to them. The difficulty here is that such self-monitoring never amounts to the self-awareness that our flesh affords us. The foundation of such self-awareness is our sense of touch. When I touch an object, I feel both its properties and my sensations. To use Husserl's examples, I feel both "the coldness of the surface of a thing and the sensation of cold in the finger" when I touch a cold object. Similarly,

in the case of a hand lying on the table, the same sensation of pressure is at one time taken as (aufgefaßt als) a perception of the table's surface (of a small part of it, properly speaking) and at another time, with a different direction of attention and another level of interpretation (Auffassungsschicht), it results in sensations of my fingers pressing on it (Ideas II, 154, translation altered).

This doubling of sensation is not yet self-awareness. For this, I must touch myself. When I do so, then, the two parts of my body have a double functioning. Functioning as a physical object, each moves and touches the other. ${ }^{5}$ Functioning as flesh, each has touch sensations with the possibility of taking them in a two-fold way. The hand, for example, that touches the other hand moves it as an external object and is felt as such. The touched hand feels the touching hand's smoothness, warmth, etc. It also, however, feels its own sensations as it is being touched. The same holds for the touching hand. The hand it touches is felt like an external thing, and it also feels internally its sensations of touching, i.e., the pressure on its fingers. As a result, each 
hand is both sensing flesh and sensed object. As a sensed object, it has its real properties. As sensing flesh, it has its localized sensations, which spread across its extent. Each hand through the other thus becomes aware of itself as a sensing object. Each is grasped as an object that, qua sensing, is also a subject. The ability of flesh to be taken as both subject and object gives it the special character of its self-awareness. At the origin of the "inner distance" that characterizes the subject-object dichotomy is the fact that on the level of touch, flesh's relation to itself is not direct, but rather mediated.

As Husserl makes clear, no other sense can substitute for touch in founding selfawareness. Take for example sight. I can regard my body, but as Husserl notes, "I do not see my body, the way I touch myself. What I call the seen Body is not something seeing which is seen, the way my body as touched is something touching which is touched." What is lacking here is "the phenomenon of double sensation," a phenomenon that could only occur if "one eye could rub past the other" - that is, if eye could touch eye (Ideas II, 155). Similarly, when I look myself in the eye with a mirror, "I do not," Husserl claims, "see the seeing eye as seeing." The eye I regard is like the eye of another. I have to employ empathy to indirectly judge that it is identical with my eye $(155, \mathrm{n} .1)$. The eye that regards me from the mirror is, in other words, experienced as an object. My seeing it does not give me a first person experience of its seeing. To have this I would have to experience its seeing as my seeing. Touch does this since the hand that is touched also feels. Here the sensations of the touched hand point back to the touching hand as touching. By contrast, the eye that I regard in the mirror is like the inanimate objects that I touch. I feel their properties, but I do not feel them feeling me. They do not return my awareness to myself. 
How, then, do I regard my eye as my own? I can do so, according to Husserl, only by touching it. Touched, it provides the "touch and kinetic sensations" that allow me to apprehend it as belonging to my body (Ideas II, 156). Such sensations are crucial. As Husserl writes, "[a] subject whose only sense was the sense of vision could not have an appearing body" (158). For my body to appear as mine, i.e., for there to be the self-awareness that makes it mine, we need "the phenomenon of double sensation." Lacking it, we are like those patients the neurologist, Oliver Sacks, describes who, on waking, attempt to make room for themselves by shoving their own legs out of bed (55). Unable to touch themselves, they react to and move their bodies like foreign objects. This can be put in terms of the "localization" that touch provides. The kinesthetic sensations of tension that I experience in moving my hand become localized because they are constantly "intermixed" with those of touch. It is through touch that I experience movement as my own. It is because the visual body coincides with the tactual that it participates in this localization, i.e., is recognized as my own. ${ }^{6}$ Without touch, then, I would have none of the abilities that allow me to unfold the world in the horizonal structures that are correlated to my movement. The kinesthetically based motivations that lie behind my bodily "I can" would fall away.

\section{III.}

One distinguishing feature of our intelligence is its ability to make objective claims. Such claims involve the object as it is in itself, the object as simultaneously available to all possible perspectives. As already noted, no individual consciousness can directly grasp this object. Qua embodied, it always manifests a first person perspective. How, then, can we speak of the object 
in itself? As Kant observed, we do this through positing other observers like ourselves. ${ }^{7}$ The horizon of possible perspectives implied by the object in itself is correlated to a horizon of possible observers similar to me but located elsewhere in the perceptual field. What I take to be objectively valid is what I and others agree on, what is "there" for all of us. ${ }^{8}$ As Eugen Fink pointed out, to follow this line of reasoning is to define "the objectivity of objects by the character - if one will - of intersubjectivity." The formulation is such "that one cannot establish between objectivity and intersubjectivity a relationship such that one or the other is prior; rather, objectivity and intersubjectivity are indeed co-original" (86). Such co-originality signifies that their grasp occurs together. Thus, the intelligence that makes objective claims for its apprehensions must also be able to grasp others as having similar apprehensions. ${ }^{9}$

How, then, do I grasp such others? In this regard, Husserl writes, "It is clear that the apprehension of the body plays a special role for the intersubjectivity in which all objects are apprehended 'objectively'" (Ideas II 86). This is because others appear to me through their bodies - more specifically, through their bodily behavior. Thus, I apprehend others as like me insofar as they behave as I would were I in their situation. As long as they do, I transfer to them my sense of my subjectivity controlling my body. Now, the fact that my own body appears to me as both sensed object and as sensing flesh plays a crucial role in the transfer. This dual character means that objective exteriority and sensing interiority pertain to the same lived body. Thus, in making the transfer, I can go from the exterior appearance of the other, i.e., the other viewed from the outside in his or her bodily behavior as sensed object, to the other's interiority, i.e., the other as sensing flesh - the other as having apprehensions as I do. Because my own body has both 
aspects, I take the other's body as also having this dual character. Assuming this, I can move from the other as object to the other as subject. ${ }^{10}$

My sense of my self as a behaving subject involves, of course, not just sensing, but also my reaction to what I sense. As such, it includes the motivating role played by my apprehensions. What I see prompts me to respond in certain typical ways to a given situation. Observing that others have similar responses, I take their apprehensions of the situation as similar to my own. ${ }^{11}$ Since the objective world, taken as the world that is there for both of us, is correlated to these similar apprehensions, my grasp of this world occurs in parallel with my grasp of others. Both are founded and continually confirmed by the similarity of our bodily behavior. What founds my awareness of this similarity is my awareness of the dual character of my own body. This, however, has its ultimate foundation in my sense of touch.

This sense is, in fact, crucial to the sense of myself controlling my body. I do not control my body the way I move external objects. Because of the localization of my kinesthetic sensations, when I move myself, I feel myself being moved. The moved arm, for example, is sensed as both mover and moved. As such, I have a sense of moving it immediately. As Husserl writes: "the body as a field of localization is ... the precondition for the fact that it is taken as ... an organ of the will," that is, as "the one and only object which, for the will of my pure ego, is moveable immediately and spontaneously" (Ideas II 159). The sense of my subjectivity controlling my body that I transfer to the other is precisely this sense of being an animate body. Recognizing the other as "like me" is recognizing him as an animate, embodied subject. My sense of this presupposes touch, since touch is what localizes kinesthetic sensations. Thus, without touch, the whole process of comparing the other's behavior to my own cannot begin. 
Without it, I cannot make the co-theses of intersubjectivity and objectivity. But this means that I cannot employ my intelligence to make objective claims. The "others" that such claims require are simply not available.

\section{IV.}

Here, it may be objected that in establishing an objective world others are there for me primarily as conversational partners. To state the obvious, I cannot see out of the other's eyes. Verbal behavior is what I chiefly rely on to judge whether other people apprehend the world as I do. In this view, what is correlated to the objective world is not perceptions but language. The common world, the world that is there for all of us, is the world that is the correlate of our common language. We ourselves are its correlates as speakers of this language. It is, in fact, as speakers of this language that we recognize one another as similar subjects. This linguistic view of subjectivity is implicit in Turing's test for artificial intelligence. In this test, a thinking machine and a person are hidden from view and communicate to the experimenter only through typed messages. Not penalizing the machine for its lack of human flesh means in this context eliminating all but its verbal behavior. When an interlocutor cannot tell which hidden speaker is a person and which is a machine, then the machine can be said to have passed the test.

The Turing test has generated a multitude of imaginative movies featuring talking computers. Despite this, the thought of a machine actually speaking as we do has an overwhelming difficulty. It ignores the actual processes involved in the learning and functioning of language. The original context of our learning how to speak involved our initial life projects such as going to the bathroom or learning how to eat at the table. These projects were 
accompanied by a constant commentary from our caregivers. Each new activity with its related objects was introduced to us with a verbal description. As a result, the objects we encounter already come clothed with verbal meanings. Such meanings, however, betray their origins by being correlated to our projects. If, for example, our project is to write, then "paper" will bear the sense of "what you write upon." If it is to start a fire, then its sense will be "combustible material." In each case, what determines sense is the object's instrumental character; it is its function as a means for the accomplishment of our projects. The point here is perfectly general. Our learning a language is determined by the fact that, as William James noted, objects only appear as correlates of the projects that reveal them (354-357). In fact, as Heidegger stresses, it is only in terms of such projects that the world appears at all, i.e., as articulated into objects with disclosed properties. ${ }^{12}$ Thus, the intersubjective character of language - the fact that it expresses meanings that we can share - points back to the intersubjective or shared character of the life projects that set the context for our learning how to speak. Granting this, we cannot abstract the functioning of language from such projects. These projects, however, were initially body projects. They involved our learning how to use our bodies to achieve our goals. Even as adults most of what we do involves this use. ${ }^{13}$ Given this we cannot abstract verbal from bodily behavior. Without the body, we would not have the projects that define language. Without it, we would lack the context required for assessing linguistic intelligence. This is because the appropriate or inappropriate use of language is ultimately determined by the activities that reveal the senses our words relate. For humans to engage in these activities, they must have bodies.

The doubts that I have raised may be put in terms of the relation of artificial to natural intelligence. Either these two are ultimately distinct in kind or else we have to say that what is 
absolutely essential to one must also be present in the other. Natural intelligence, I have argued, involves having a body. Given its evolutionary history, this is, of course, hardly surprising. Yet, if we accept this, then we have to say, contrary to Turing, that we cannot draw "a sharp line between the physical and the intellectual capacities of a man." A truly "intelligent machine" would have to possess both capacities.

\section{Notes}

${ }^{1}$ As Merleau-Ponty puts it, "the positing of one single object, in the full sense, demands the compositive bringing into being of all these experiences in one act of manifold creation. Therein it exceeds perceptual experience and the synthesis of horizons" (71).

${ }^{2}$ I would like to express my gratitude to Prof. Rudolf Bernet, Director of the Husserl Archives, for permission to cite from the Nachlaß.

${ }^{3}$ As Husserl puts this: The sensations that give one the extended features of the thing are "related to motivating series, to systems, of kinesthetic sensations." The two are connected in an "if ... then" relation - i.e., if I have a set of kinesthetic sensations, then a given set of sensations of the object will also follow. In Husserl's words, they are all "of the following type: if the eye turns in a certain way, then so does the 'image'; if it turns differently in some definite fashion, then so does the image alter differently, in correspondence" (Ideas II 63).

${ }^{4}$ In Husserl's words, "An apprehension of a thing as situated at such a distance, as oriented in such a way, as having such a color, etc., is unthinkable, as can be seen, without these sorts of relations of motivation" (Ideas II 63).

${ }^{5}$ In Husserl's words, "each is, then, for the other an external thing that touches and works upon it" (Ideas II 153).

${ }^{6}$ In Husserl's words, "Obviously, the body is also to be seen just like any other thing, but it becomes a body (Leib) [that is mine] only by incorporating tactile sensations, pain sensations, etc., - in short, by the localization of the sensations as sensations" (Ideas II 158-9).

${ }^{7}$ For Kant, objective validity and necessary universality mutually imply each other. In Kant's words, the first implies the second "because when a judgment agrees with the object, all judgments concerning the object must agree with each other." In other words, insofar as each judgment states the same thing with regard to the object, each has the same content. Their 
agreement with the object is their universal mutual agreement. By parity of reasoning, the second implies the first, for otherwise, "there would be no reason why other judgments would necessarily have to agree with mine, if it were not the unity of the object to which they all refer and with which they all agree and, for that reason, must agree among themselves" (vol. 4, 298, italics added).

${ }^{8}$ As Husserl puts this: "Considered as objective, the sense of the being of the world and, in particular, the sense of nature includes ... thereness-for-everyone, thereness as always cointended by us whenever we speak of objective actuality" (Cartesianische Meditationen 124, italics added). What we have, in fact, is an equivalence between the two "worlds," since for Husserl, the intersubjective world is also an objective world. It is "a world for everyone, accessible to everyone in its objects" (123, italics added).

${ }^{9}$ Husserl thus affirms: "In every case the exhibition of any apprehended objectivity whatsoever requires a relation to the apprehension of a multiplicity of subjects sharing a mutual understanding" (Ideas II 86).

${ }^{10}$ As Dan Zahavi puts this point, "my bodily self-exploration permits me to confront my own exteriority ... It is exactly the unique subject-object status of the body, the remarkable interplay between ipseity and alterity characterizing body-awareness that provides me with the means of recognizing other embodied subjects" (161).

${ }^{11}$ Such apprehensions, of course, are not from my "here," but from "there" where the other is. Thus, when I take others' apprehensions as similar to mine, then, as Husserl notes, this assumes "that, perceiving from the there, I should see the same things, only in correspondingly different modes of appearance such as would pertain to my being there" (Cartesianische Meditationen 146).

12 This is why, as Heidegger writes, "World is only, if, and as long as Dasein exists" (170). As an "equipmental totality," which is uncovered by our projects, it depends on us (163-4). Such a world, of course, is not "nature," which "always already is." The elements of nature become objects in our "world," when through our projects we disclose them (169).

${ }^{13}$ A possible exception to this is mathematics - the language that has a privileged place in many contemporary accounts of artificial intelligence. 


\section{Works Cited}

Fink, Eugen. "Discussion - Comments by Eugen Fink on Alfred Schutz's Essay, 'The Problem of Transcendental Intersubjectivity in Husserl."' Collected Papers III. By Alfred Schutz. Ed. I. Schutz. Phaenomenologica, no. 22. The Hague: Martinus Nijhoff, 1966.

Heidegger, Martin. The Basic Problems of Phenomenology, Revised Edition. Trans. Albert Hofstadter. Bloomington: Indiana University Press, 1988.

Husserl, Edmund. Ideas Pertaining to a Pure Phenomenology and to a Phenomenological Philosophy, Second Book. Trans. R. Rojcewicz and A. Schuwer. Dordrecht: Kluwer Academic Publishers, 1989.

—. Cartesianische Meditationen. Ed. S. Strasser. The Hague: Martinus Njhoff, 1963.

—. "Ms. C 16 IV"; "Ms. D 12 II." Nachlaß. Husserl Archives.

James, William. "Reasoning." Psychology, Briefer Course. New York: World Publishing Co., 1948. 354-57

Kant, Immanuel. "Prolegomena." Kants gesammelte Schriften, 23 Vols. Berlin, 1910-55.

Merleau-Ponty, Maurice. Phenomenology of Perception. Trans. Colin Smith. London: Routledge \& Kegan Paul, 1962.

Turing, A.M. "Computing Machinery and Intelligence." Mind 59, no. 236 (1950): 433-460.

Sacks, Oliver. The Man Who Mistook his Wife for a Hat and Other Clinical Tales. New York: Simon and Schuster (Summit Books), 1986.

Zahavi, Dan. "Beyond Empathy." Between Ourselves, Second-Person Issues in the Study of Consciousness. Ed. Evan Thomson. Journal of Consciousness Studies 8, nos. 5-7 (2001). 